\title{
A STUDY ON THE CORRELATION OF LABOR JOB SEARCHING BEHAVIORS BY ASYMMETRIC INFORMATION PSYCHOLOGICAL ERRORS
}

\author{
Wang, Lai-Wang1, Chen, Chiu-Hsiung ${ }^{2}$, Wu, Cheng-Chung ${ }^{3 *}$ \\ ${ }^{1}$ Associate Professor, Department of Industrial Engineering Management National Kaohsiung University of Science and Technology, Taiwan \\ ${ }^{2}$ Ph D. Student, Department of Industrial Engineering Management National Kaohsiung University of Science and Technology, Taiwan \\ ${ }^{3}$ Associate Professor, Department of Finance Suqian College, China. \\ *Corresponding Author Email: wu_0110@yahoo.com.tw
}

\section{ARTICLE DETAILS}

\section{Article History:}

Received 12 November 2017 Accepted 12 December 2017 Available online 1 January 2018

\section{ABSTRACT}

Unemployment rate in the world wide has been raised under the influence of the financial crisis. With the high unemployment rate, there are a large number of jobseekers in the current society, therefore, this study is aimed at job seekers, hoping to understand the impact of job search behavior by the asymmetric information psychological errors. This study investigates and analyzes demographic variables, asymmetric information psychological errors and job-hunting behaviors, it found that different age, gender, education and marriage have significant differences in asymmetric information psychological errors. In job research, the statistical test results of regression models show that, uncertainty in risk, optimism, and the herd behavior on job-searching behavior were positively correlated. The study found that the uncertainty of the size of the risk will affect the behavior of job-seekers, when the greater job risk, job seekers are still willing to fight in a contrarian environment; at the time of job search, the level of optimism will affect judgment of job seekers in the choice of work. They will easier to find a job, willing to accept all kinds of industries and hold a positive attitude, but when they choose the job, they will regret due to lack of thinking; they also would easy to affect by the colleagues or environment, easy to follow the advisement when searching the job, most of them are introduced by acquaintances or follow in the footsteps of the colleagues. This study attempts to understand the impact on job searching behavior of asymmetric information psychological errors which from job-seekers' decision-making in face of various decisions, to provide reference for job seekers in the future.

\section{KEYWORDS}

Asymmetric Information, Psychological errors, Labor, Job-searching behavior.

\section{INTRODUCTION}

\subsection{Background}

The global economy is now affected by the financial turmoil; the rate of economic growth has gradually declined and slowed down. There are so many enterprises run poor, or even bankruptcy, although the lesser can keep the company from going bankrupt, to save on costs and unnecessary waste, they choose layoffs. As a result, all enterprises took drastic measures to implement the layoffs, and some even ignored the employee's seniority in experience and directly put into the list of layoffs.

Second, the unemployment rate has been continuously increasing in recent years that also affect young students who face unemployment after graduation. Even highly educated job applicants who already graduated from doctor's degree, they must adjust themselves to asymmetric information psychological errors for living. They should not seek highly paid jobs for their high academic degrees, but to pull themselves out of their positions to balance their needs and force themselves to do the job which just pay a little. In recent years, research has shifted from whether the wage level provided by enterprises could be attractive to the employed, to whether job seekers are willing to change their asymmetric information psychological errors to get a job. In today's high unemployment rate, both college freshmen and employees laid off by the company are facing great challenges in the job search process, job seekers often rely on the subjective corporate image to speculate about their work environment and as a basis for employment decision-making. This research would like to understand the impact of asymmetric information psychological errors for job search behavior from the results which job seekers were determined when they face choices, including personal growth background for the job search tendencies, the accumulation of past work experience whether affect the job-seeking behavior, the public's decision whether the impact of job-seekers decision, as well as excessive confidence and optimism whether affect the job seekers attitude, etc. The results of this research are intended to provide some references to the job seeker in their future job search process.

\section{LITERATURE REVIEW}

\subsection{Psychological errors}

The psychological errors discussed in this research are disposal effect, uncertainty in risk, representative bias, frame effect, mental account and self-control ability, empirical effect, overconfidence, optimism and herd behavior. The related literatures are discussed as follows:

\subsubsection{Disposal effect}

A couple researchers created the word "disposal effect", they thought the pain of personal aversions is better than the creating profits, so when faced with a situation of failure, individuals are willing to go for it in order to avoid losses [1]. In other study also proposed a value function to explain the reason of actors, the graph of the value function is a graph of values and results, with the center point being the reference point for the transaction, resulting from the individual's subjective perception of the transaction, the value of the cost function at loss is the curve up, and the profit of the value function curves is downwards [2]. The opposite happens between the two directions, the only difference is the steepness, and the value of loss function is steeper than the profit one.

\subsubsection{Uncertainty in risk}


Psychologists point out, risk attitude is an inherent tendency, people tend to show irrational short-sighted behavior, such as excessive concern and worry about the subtle risks of life, these risks are not important to their livelihood, and average disperse into a long time, showing insignificant; Conversely, Some of the major risks in life, they carelessly instead. Some researcher found, "there is a fair coin toss game, where you can get 10 for a front but pay 10 for tails, you can choose to play or not play? "If you choose to play, that is willing to take risks; if you choose not, that is reluctant to take risks [2]. As mentioned in the literature, risk attitude is an inherent tendency, when making decisions, the decision makers often only care about the interests what they see but cannot think carefully about the significant risks in the future. The researcher probes into the risk uncertainty to explore whether these psychological errors affect to the job search behavior of job seekers.

\subsubsection{Framing effect}

A researcher interpreted the framing is "the framework is a description" Framing dependence is the individuals making decisions under the influence of the way to present information [3]. Thaler thought that human beings encode things in ways that assume the best way to maximize their happiness and propose the principle of four happy frameworks; The first one is segregate gains, because the profit is concave function; The second one is integrate losses, because the loss is a convex function; The third one mergers integrate smaller losses with larger gains, in order to compensate for the loss of mischief, and fourth is segregate small gains from larger losses, since the profit taking function is steep at the outset, the benefit of a small profit can be offset by the utility of large losses [4]. In the literature, when decision makers face a problem, they are often guided by the way in which the problems are presented, without being able to penetrate the appearance of the problems and go into the reality of the events. This research will analyze the impact of jobseekers on the job searching behaviors of the framework effect.

\subsubsection{Mental account}

A couple of researcher has defined a mental account is a framework for evaluating things, and thought a mental account is a process of coding, classifying and evaluating things $[4,5]$. A researcher also thought there are three important characteristics of the value function in Prospect Theory that are the indispensable elements of a mental account; Firstly, the value function fully illustrates the relative relationship between profit and loss at a reference point; Secondly, the profit and loss functions both show a decrease in sensitivity; Thirdly, loss of disgust [4]. The role of the value function in a mental account is to describe how events being perceived and coded at the time of making a decision. Many different accounts exist in the cognitive system of human beings. When decision makers encounter a problem, they often put the question into a specific account automatically or set up a new account alone. In the process of making a decision, the account may also affect the decision maker. In this research, mental account and some related behaviors of job seekers are studied, whether job seekers in the job searching process will be affected by mental accounts.

\subsubsection{Representativeness Bias}

Tverskyand Kahneman pointed out, when the people faced a complicated problem, they may not pursuit the best solution, but may take a step back to pursuit of second best solution to meet the demand in order to reduce the cost of decision-making (including time) [6]. Therefore, people may not care whether the decision they made in the daily life is best or not, but through quick thinking, they could make decisions and judgments quickly. As mentioned in the literature, people may not pursuit the best solution, but may take a step back to pursuit of second best solution to meet the demand in order to reduce the cost of decision-making or always choose to save time when they judge the investment target. However, this study aims at this behavior by applying representative bias to job searching behaviors and verifying whether representative bias would also affect the job searching behavior.

\subsubsection{Empirical effect}

The reference information is mainly personal experience; no matter it is a positive experience or a negative one. If people had a failure experience in the past, then the choice tendency to escape when they met similar situations in the future, this is called Snake Bite Effect; but if got profits, they bear the risk turned positive, is called House Money Effect; and it is possible to avoid "losing", on the contrary they would braver to pursue the risk and increase its mark in order to achieve a profit and loss of two flat, this is called Trying to Break Even Effect. A couple of researcher extended the spirit of Laughunn and Payne to investigate how the previous gains and losses affected decision making [7,8]. Research shows that the extent of loss avoidance will be affected by the previous losses or gains, in the case of loss after gain, people will suffer less than usual because their impact is offset by their previous gain, but if losses are followed by losses, the degree of distress will deepen as the sensitivity to the next loss will increase as a result of the previous loss. Thus, the choice of investor will be influenced by the previous experience, whether positive or negative. Empirical effect refers to the judgment and choice of decision-makers affected by the experience of personal gain or loss, making decisions deviate from the rational phenomenon, and would affect the snake bite effect or the sweetness effect, this research places empirical effects on job searching behavior and explores whether job-seekers are affected by empirical effects in the job searching process.

\subsubsection{Overconfidence}

People often overestimate their own knowledge and ability; some group researchers called this situation is overconfidence [9]. When people are overconfident about their own judgment, they often cannot recognize their lack of capacity and thus lose the opportunity to modify or improve the accuracy of judgment, producing in overconfidence and more frequently making wrong decisions. There also, some researchers thought there are quite significant differences in optimism and self-confidence between the two sexes, the optimistic which for the coming year to reach the personal investment target, male investors were significantly more optimistic than females, and men's future pay expectations also higher than women, male investors are also significantly higher than women in the degree of self-confidence of whether could beat the broader market. As mentioned in the literature, when people are overconfident about their own judgment, they often cannot recognize their lack of capacity and thus lose the opportunity to modify or improve the accuracy of judgment, producing in overconfidence and more frequently making wrong decisions, the research will deeply discuss in what kind of mistakes would producing in the job searching by overconfidence.

\subsubsection{Over-optimism}

People often hold unrealistic optimism about the outcome they get in the future or a simple chance event (such as lottery), believing themselves to be luckier than others, which makes them produce higher expectations than actual. Some researchers also thought people usually are optimists, who often think themselves talented and overestimate their control of the disadvantage situation [10]. As mentioned in the literature, optimists are often surprised by what happened that unexpected, this research will be discussed what will happen in job searching of the optimists.

\subsubsection{Herd behavior}

The gathering of objects is a common phenomenon in human society, there is a contemporary mainstream trend in any space-time environment. However, imitation is a human instinct, so the various decisions which they made often follow the opinions of others or are influenced by others; therefore, the production of the herd mentality is common in people's lives and not limited to trading in the market. A researcher believes that make the same decision after following others' action is conformity. More specifically, conformity is the phenomenon of seeing a group of people collectively making the same decisions [11]. As mentioned in the literature, the herd mentality is widespread in the people's life, so the various decisions which they made often follow the opinions of others or are influenced by others, and not limited to trading in the market, this research discuss the herd behaviors of job seekers.

\section{$2.2 \quad$ Job searching behaviors}

The so-called job searching behavior is a specific behavior which refers to the time and endeavor paid through job search to obtain a specific job opportunity in the job market, separated job searching behavior into many parts; (1)Sources of information: Individuals exploit the exploration of the environment and their own strengths and weaknesses to find information;(2) Exploration methods: Investigate the methods of job opportunities are random or systematic; (3) The breadth, scope and quantity of the obtained information; (4) The endeavor that individual cost on the job searching behavior: the cost of job searching, such as buy newspapers and magazines which cover on information for jobs, time costs, etc.; (5) Individual's confidence in the success of job hunting; (6) the pressure during job searching. The purpose of construct professional preferences which depend on the choice of job characteristics is to want to get an ideal working condition. In the permitting conditions of market for human resources supply and demand, the job selection is expectation about an individual for the job characteristics whether could meet their own needs, salary remains an important consideration for most people 
choosing a job, because it could be varied according to industry, region and company, especially for fresh people whom are lack of understanding about the workplace ecology because they lack previous work as background reference. This research aims at finding the job searching processes of research objects which be affected by the salary level, educational background, sources of information, as well as psychological errors.

\section{RESEARCH METHOD}

\subsection{Research object}

The main research objects Taiwan citizens, to discuss the relationship between the job searching behavior and psychological errors of Taiwan citizens. A total of 300 questionnaires were sent out in this research, with 276 questionnaires recyclled.5 invalid questionnaires were deducted and 271 were valid questionnaires.

\subsection{Questionnaire}

After discussing relevant literature on psychological errors, this research found that psychological errors do affect individual decision-making on job searching behavior. This research strengthens the reliability of experimental research and conducts data collection by questionnaire, which can be investigated in the natural situation without human control. Psychological errors were investigated in this research were as follows; Disposal effect, uncertainty in risk, representative bias, frame effect, mental account and self-control ability, empirical effect, overconfidence, optimism and herd behavior.

After modified the literatures into a questionnaire by experimental method, the Taiwanese as the test subjects, to try to understand the impact of psychological errors on the job searching behavior. In addition to the interviewees' basic information (personal traits), this questionnaire mainly includes two major parts: psychological errors and job searching behavior. There is an explanation of the questionnaire and operational definitions for each variable relevant for this study as follows:

\section{(1) Psychological errors}

The questionnaire of this part is adapted from the living or financial situation that simulated for explaining certain psychological errors. There are nine psychological errors in this research, a total of 25 questions.

\section{(2) The scales of job search behavior}

The "Job search behavior scale" contains "salary level", "environmental impact", "whether the academic qualifications affect job search options", "information source" "experience accumulation", "relevant certification", "family", "peer influence" eight subscales. Using the (Likert Scale) fivepoint scale, the total scale is 23 items. In scoring, the scale uses Likert Scale five-point scale, according to the participants' own subjective feeling on the items which were divided into five options scale, 5 points represent "very important $100 \%$ " said participants attaches great importance to the subjects, 4 points represent "important 75\%" said participants think highly of the factors, 3 points on behalf of the "ordinary important 50\%", said the participants average value of the factors, 2points represent "slightly important $25 \%$ " said factors a little attention to the subjects and 1 point means " not important $0 \%$ "indicates that the subject does not pay attention to this factor. There is no reverse problem in this scale. The higher score means the higher attention of the participants has paid to the scale, whereas the lower means the less importance it attaches to the scale.

\section{THE RESULTS OF EMPIRICAL ANALYSIS}

\subsection{The single-factor variation and independent sample $T$ test of demographic variables}

In this research, single factor variance analysis and independent sample T test were used to explore the correlation between population statistical variation and various psychological errors, mainly verify: whether there is a significant correlation between demographic variables and job searching behavior. Gender analysis and disposal of psychological errors, empirical effects, optimism by single factor analysis of variance was $0.010,0.002,0.027$, at significant levels of $p<0.05$, there were significant differences between groups of different genders. Analysis of the age of the psychological error representative bias by single factor analysis of variance was tested as 0.006 , at the significant level of $p<0.01$, there were significant differences between groups of different ages. Differences between groups in different academic qualifications found that there were significant differences in academic records and representative biases in different academic qualifications that the psychological errors of academic qualifications were analyzed by single factor analysis of variance. Analysis of Marital Psychological Errors, the differences between groups in different marital status found that the significant differences in the empirical effects of different marital status categories.

\subsection{Regression analysis}

Using regression analysis, the predictive power of job-seeking behavior of the outcome variables was explored in the past due to the effects of disposal effect, uncertainty in risk, framing effect, mental account, representativeness bias, empirical effect, over confidence, optimism, herd behavior, to observe whether it has reached a significant level, taking job effects as disposal effect, uncertainty in risk, framing effect, mental account, representativeness bias, empirical effect, overconfidence, optimism, herd behavior as predictive variables, the use of forced enter by regression equation establishment and testing, in order to detect the causal relationship between the variables, with the coefficient of determination $R^{2}$ to verify the predictive variables of the effective variable of the overall explanatory power of the size. The results are shown in the table.

Table 1: Regression Analysis of Psychological Errors on Job Searching Behavior

\begin{tabular}{lllll}
\hline & Regression Coefficient & Standard Error & T-value & Sig. \\
\hline (Constant) & 2.905 & 0.282 & 10.298 & $0.000^{* *}$ \\
Disposal effect & 0.049 & 0.038 & 1.283 & 0.201 \\
Uncertainty in risk & 0.060 & 0.027 & 2.188 & $0.030^{* *}$ \\
Framing effect & 0.039 & 0.079 & 0.492 & 0.623 \\
Mental account & -0.050 & 0.082 & -0.603 & 0.547 \\
Representativeness bias & -0.027 & 0.042 & -0.654 & 0.514 \\
Empirical effect & -0.035 & 0.066 & -0.531 & 0.596 \\
Overconfidence & 0.019 & 0.035 & 0.536 & 0.592 \\
Optimism & 0.064 & 0.030 & 2.110 & $0.036^{* *}$ \\
Herd behavior & 0.070 & 0.031 & 2.255 & $0.025^{* *}$ \\
Disposal effect & 0.039 & 0.079 & 0.492 & 0.623 \\
\hline
\end{tabular}

Adjusted $\mathrm{R}^{2}$

0.095

F-statistic

3.050

** indicates significant at a significant level of 0.05 
It can be seen from Table 1 that the uncertainty in risk, optimism and herd behavior overall $\mathrm{R}^{2}$ for job searching behavior is 0.095 , which shows uncertainty in risk, optimism and herd behavior have $9.5 \%$ interpretation of job searching behavior, F value of 3.050 reached a significant level (p $<0.05$ ). In other words, uncertainties in risk, optimism, and herd behavior have significant explanatory power for job searching behavior.

\section{CONCLUSION AND SUGGESTION}

\subsection{CONCLUSION}

This study analyzes the demographic, psychological and job-seeking behaviors in three dimensions and found the following important conclusions:

(1) Relevant influence of demographic variables on psychological errors: Gender has significant differences in the disposal effect, empirical effect and optimism.

The analysis of this study argues that men have a slightly greater effect on disposal effect than women, showing that men more like the joy with creating profits than the painful of losses, and that modern men are also becoming more and more conservative, that also represented modern men are no longer strong like in the past, emphasizing the equal rights of men and women in the era, men sometimes preferring to choose the second-best way than the best way. In terms of "empirical effects", women are slightly larger than men. This research argued and proved that women are mainly based on past experiences to solve problems. Women's power was weaker in the past, so that most women would not think the way to solve new problems with previous experience in major. Because the respondents in this research were preferred to young people, it also proved that modern women are different from the past that they tend to believe in their past experiences, it represents the progress of era. People often hold unrealistic optimism about the outcome they get in the future or a simple chance event (such as lottery), believing themselves to be luckier than others, which makes them produce higher expectations than actual, women tend to think more optimistic. Perhaps the pressure of modern men is relatively large, leading to optimistic of men regardless of employment or love is not as good as before, the confidence of them are greatly reduced, the advent of women's era may also be one of the reasons leading to this result.

There was a significant difference of age to "representativeness errors". According to the results of the research, young people under 20 years of age had the lowest significance while those aged 41 to 51 were significantly higher. Thus, the older age, the more likely to produce representativeness errors. This research argued that there would be a considerable relationship between past education and social ethos, and the younger generation is indeed more open-minded than past which makes such significant differences.

There is a significant structural discrepancy of academic qualifications to mental accounts and representativeness bias. Mental account, in turn, has the highest average of below middle school and the lowest average of high school graduate which stands the cognitive systems of the decisionmakers below middle school are generated through the experience of elders and are independent account of job-searching behavior; However, decision-makers in the high school are closer to the job-hunting stage and have already conducted a series of careful evaluations on job-searching. Therefore, job-searching behaviors are less affected by independent accounts. In addition, the average number of representativeness bias is highest in the high school, but the average of the institutes is the lowest, that is, when the decision-makers on behalf of high school job-searching could be from the experience of the outside world or others, or the knowledge they have learned in the past, so such decision-makers in the face of job searching are also affected by their own impression, however, decision makers at the institute are less affected by their own impression due to their rich working experience. They think that the job market is not just based on the existing impression.

Different marital status categories have significant differences in terms of empirical effects. Among them, the average number of empirical effects is higher in married people, and unmarried people is lower, that represented the experience of being married is rich in their own experiences. So, the behavior in the process of seeking employment is often the subjective experience of their own.

(3) The correlated influence of psychological errors on job searching behavior

The statistical test results of regression model show that uncertainty in risk, optimism and herd behavior are positively correlated with jobseeking behavior. Uncertainty about the risk will show irrational behavior which means the uncertainty of the risk will affect the judgment when searching employment, when applying for the greater risk of a job, job seekers are still willing to take the risk of a big threat, and they would like to even in a contrarian environment. Personal optimism makes it easy to overestimate their own knowledge, underestimate the risk and exaggerate the ability to control the incident, that is, the level of optimism will affect the ability of job seekers in the selection of work. When a person is more optimistic, would be easier to find a job, and they are willing to accept a variety of industries with a positive attitude, however, they would also a lack of thoughtful consideration in the selection of work, and may choose a work which they cannot able to do, or because they underestimate the risk of seeking a job, thus causing their own losses. Birds of a feather flock together is a common phenomenon in human society, there is a contemporary mainstream trend of thought in anytime and space, while imitation is the instinct of mankind, the various decisions which they made would often follow the opinions of others or were influenced by others. In another word, when a peer, a friend or the environment turns a particular industry into a hot industry, job seekers often choose the same job after following the upsurge that hoping they can integrate into popular topics and avoid being left out because of they cannot understand when talking to others. As modern people are easily influenced by others, they will listen to those who give their opinions and will inevitably want to find someone who is familiar with their job searching. This can reduce the difficulties which they have to overcome in the new job environment.

\subsection{Suggestion}

Looking back at the entire research process, this research explored the impact of psychological errors on job-seekers and provided relevant opinions on "job seekers" and "businesses and manufacturers". The economic downturn continues to be sluggish and the economy is still in a recession for the global economic change, but the good news is that the recession has slowed down, many large-scale enterprises and major industrial zones adjust the required cost burden by laying off staff in order to survive the recession. As a result, it is hard to seek a job, media and television often say that university graduation amounts to unemployment When aspiring job seekers fail to find jobs repeatedly and feel uncertainty about the future, job seekers are willing to fight of seeking a stable job regardless of academic qualifications, age, the different qualification of a job, and salary. That would have many cases about wasting their talents in a job and the enthusiasm for life will also be buried. As a result, job seekers will lose the passion to their career. On the contrary, the number of people taking part in the national public examinations is increasingly soared. This is worth thinking when born in a stable environment; it would lack the competitiveness of other countries while other countries are making progress. In the time of financial squeeze, the number of job vacancies released by enterprises is fewer, when facing many job seekers, a lot of energy must be taken in the screening process and large risks must also be borne. Enterprises must face the optimism, herd behavior, uncertainty in risk, etc. of job seeks, when the job seeks are too optimistic, the attitude of doing things tend to be arbitrary, take laissez-faire to details and lack of thoughtful in decision-making which seriously affect the development of the company. The herd mentality is lack of independent judgment, easy to get lost, the job seeker would feel painful after choosing an unsuitable job and always hard to find their own stage. And it may not a good thing to company that with peers, mates serving in the same place, when feeling good, everyone could work exhilarating, but when the emotional disputes outside the work that could also affect the working atmosphere and the efficiency of work. The companies are easily blinded by the empirical effect, there are often take a part for the whole and restrict the framework from the experience that will distinguish the good or bad by academic qualifications. However, the research pointed out that for some highly educated job seekers, overconfidence would lead to lower plasticity, the attitude is less active, which is not the needs of company, so employers can use some corresponding psychological tests, job interviews and observe during the trial period, to select the most suitable person for the job.

\section{REFERENCES}

[1] Shefrin, H., Statman, M. 1985. The Disposition to Sell Winners Too Early and Ride Losers Too Long: Theory and Evidence. Journal of Finance, 40, 777-790.

[2] Kahneman, D., Tversky, A. 1979. Prospect theory: An analysis of decision under risk. Econometrica, 47, 263-291.

[3] Shleifer, A. 2000. Inefficient Market, Oxford: Oxford U. Press.

[4] Thaler, R.H. 1999. Mental Accounting Matters. Journal of Behavioral Decision Making, 12, 183-206. 
[5] Tversky, A., Kahneman, D. 1981. The Framing of Decisions and the Psychology of Choice. Science, New Series, 211 (4481), 453-458.

[6] Tversky, A., Kahneman, D. 1974. Judgment under Uncertainty: Heuristics and Biases, Science, 185, 1124-1131.

[7] Thaler, R.H., Johnson, E. 1990. Gambling with the House money and Trying to Break Even: The Effects of Prior Outcomes on Risky Choice. Management Science, 36, 643-660.

[8] Laughunn, D.J., Payne, J.W. 1984. The impact of sunk outcomes on risky choice behavior. INFOR, 22, 151-181.
[9] Lichtenstein, S., Fischhoff, B., Philips, L.D. 1982. Calibration of probabilities: The state of the Art to 1980, in Judgment under Uncertainty: Heuristics and Biases, D. Kahneman, P. Slovic, A. Tversky (eds.), Cambridge, England: Cambridge.

[10] Kahneman, Riepe. 1998. Aspects of investor psychology. Journal of Portfolio Management, 24, 52-65.

[11] Banerjee, A.V. 1992. A simple model of herd behavior. Quarterly Journal of Economics, 107 (3), 797-817. 